\title{
Bone Health in Chronic Kidney Disease-Mineral and Bone Disorder
}

\section{A Clinical Case Seminar and Update}

Aleksova $\mathrm{J}^{1,2,3.4}, \mathrm{Ng} \mathrm{KW}^{4}$, Jung $\mathrm{C}^{4}$, Zeimer $\mathrm{H}^{4}$, Dwyer $\mathrm{KM}^{5}$, Milat $\mathrm{F}^{1,2,3}$ \& MacIsaac $\mathrm{RJ}^{4,6}$

1. Hudson Institute for Medical Research, Clayton 3168, Australia

2. Department of Medicine, Monash University, Clayton 3168, Australia

3. Department of Endocrinology, Monash Health, Clayton 3168, Australia

4. Department of Endocrinology \& Diabetes, St Vincent's Hospital Melbourne

5. School of Medicine, Faculty of Health, Deakin University, Burwood, Victoria, Australia

6. Department of Medicine, University of Melbourne

Correspondence: Dr Jasna Aleksova MBBS (HONS), FRACP

Endocrinology Department, Monash Health, 246 Clayton Rd, Clayton, VIC 3168, AUSTRALIA. Email: Jasnaaleksova@hudson.org.au

\section{Pages: 29}

\section{Review word count: 3464}

\section{Abstract word count: 155}

Tables: 3

Figures: 2

\begin{abstract}
This is the author manuscript accepted for publication and has undergone full peer review but has not been through the copyediting, typesetting, pagination and proofreading process, which may lead to differences between this version and the Version of Record. Please cite this article as doi: 10.1111/imj.14129
\end{abstract}

This article is protected by copyright. All rights reserved. 
The metabolic abnormalities affecting bone in the setting of chronic kidney disease (CKD) are complex with over-lapping and inter-acting aetiologies and have challenging diagnostic and management strategies. Disturbances in calcium, phosphate, fibroblast growth factor 23, parathyroid hormone $(\mathrm{PTH})$ concentrations and vitamin D deficiency are commonly encountered and contribute to the clinical syndromes of bone disorders in CKD including hyperparathyroidism, osteomalacia, osteoporosis and adynamic bone disease. Mineral and bone abnormalities may also persist or arise de novo post-renal transplantation. The Kidney Disease Improving Global Outcomes (KDIGO) organisation describes these mineral metabolism derangements and skeletal abnormalities as 'CKD Mineral and Bone Disorder' (CKD-MBD). Patients with this disorder have an increased risk of fracture, cardiovascular events and overall increased mortality. In light of the recently updated 2017 guidelines from the KDIGO, we present a clinical case-based discussion to highlight the complexities of investigating and managing the bone health of patients with CKD with a focus on these updates.

Key words: Chronic Kidney Disease, Metabolic bone disease, Fractures

\section{THE CASE}

\section{$\underline{\text { History and Investigations }}$}

The patient was a 69-year-old man with insulin-requiring type 2 diabetes mellitus for 20 years, complicated by retinopathy, neuropathy and nephropathy. Other medical co- 
morbidities included obesity (body mass index $31 \mathrm{~kg} / \mathrm{m}^{2}$, normal $<25$ ), hypertension, hyperlipidaemia, gastritis and obstructive sleep apnoea.

He developed chronic kidney disease (CKD) secondary to diabetic nephropathy and received haemodialysis (HD) for 5 years prior to a cadaveric renal transplant in August 2012. CKD was complicated by secondary hyperparathyroidism that was managed with phosphate binders and calcitriol, and subsequently he developed persistently low normal parathyroid hormone $(\mathrm{PTH})$ values $(22-34 \mathrm{pg} / \mathrm{ml})$ for years whilst on dialysis. Immunosuppression postrenal transplantation consisted of induction therapy with basiliximab followed with maintenance therapy of tacrolimus, mycophenolate and prednisolone. Prednisolone was commenced at a dose of $30 \mathrm{mg} /$ day weaning by $2.5 \mathrm{mg}$ every 2 weeks commencing at 3 weeks post-transplant. Graft function plateaued at an estimated Glomerular Filtration Rate (eGFR) of $44 \mathrm{ml} / \mathrm{min} / 1.73 \mathrm{~m}^{2}$. There were no episodes of acute rejection. His post-operative course was complicated by unstable glycaemic control, prostatitis, shingles and a deterioration of his pre-existing proximal myopathy.

Five weeks post-renal transplantation, he developed acute onset back pain after sliding off a low stool in the shower from a sitting position. A lateral lumbar x-ray showed an acute crush fracture at the first lumbar vertebrae with $>50 \%$ loss of anterior vertebral height. Comparison with previous imaging confirmed that this fracture was acute. He had no history of previous clinical fractures. 
His acute inpatient management comprised of analgesia, physiotherapy and commencement of cholecalciferol and he was booked for outpatient metabolic bone clinic follow up. His medications at the time of his clinic appointment are listed in Table 1. Prednisolone dose at the time of fracture was $17.5 \mathrm{mg}$ and at clinic was $12.5 \mathrm{mg}$ daily. A Dual Energy X-ray Absorptiometry (DXA) scan showed a T-score of positive 0.3 standard deviations at the lumbar spine and T-score of negative 2.7 standard deviations at the femoral neck as shown in Figure 1 (osteoporosis defined by the World Health Organisation as a T-score negative 2.5 or less) (1). A summary of his blood results prior to the transplant, during his inpatient stay and then during follow up in metabolic bone clinic are provided in Table 2. 
BONE HEALTH IN PATIENTS WITH CHRONIC KIDNEY DISEASE- MINERAL AND BONE DISORDER (CKD-MBD)

\section{$\underline{\text { Introduction }}$}

With progressive renal deterioration, there are increasing abnormalities of bone and mineral metabolism including perturbations in calcium, phosphate, fibroblast growth factor -23 (FGF23), PTH and vitamin D homeostasis. CKD-MBD was first coined following the Kidney Disease Improving Global Outcomes (KDIGO) Controversies Conference on Definition, Diagnosis, and Classification of Renal Osteodystrophy, defining it as a systemic disorder of mineral and bone metabolism due to chronic kidney disease (CKD), manifested by one or combination of:

- Abnormalities of calcium, phosphate, PTH, or vitamin D metabolism

- Abnormalities in bone turnover, mineralization, volume, linear growth, or strength

- Vascular or other soft tissue calcification

Furthermore, it was recognized this complex interaction leads to an increased risk of fractures, cardiovascular disease and overall increased mortality (2).

CKD-MBD is a clinical syndrome that encompasses the original term 'renal osteodystrophy' used to define histomorphometric bone abnormalities of bone turnover, mineralization and volume. Since this classification, the last 10 years have seen a plethora of research evaluating diagnostic and therapeutic interventions targeting CKD-MBD, commanding the KDIGO to update their original 2009 guidelines to reflect the current state of evidence. The remainder of this review will provide an overview of bone health in CKD-MBD highlighting changes to 
the recently published 2017 KIDGO guidelines on CKD-MBD (3). The patient's management is discussed in light of these clinical updates at the conclusion of the article. A detailed discussion regarding phosphate control, vascular calcification and cardiovascular outcomes are beyond the scope of this review.

Although the bone abnormalities seen in CKD-MBD result from interacting and over-lapping aetiologies associated with mineral disturbances they are broadly divided into low and high turnover bone disease states. Osteomalacia, adynamic bone disease (ABD) and aluminium bone disease characterize low bone turnover states in CKD. Osteomalacia results from inadequate mineralization of osteoid due to a relative calcium and or phosphate deficiency. This was previously seen in patients administered long term aluminium containing phosphate binders or aluminium based dialysates, however, the osteomalacic bone lesions (and other encountered bone pathologies) associated with aluminium bone disease, are now a rare entity with the introduction of aluminium-free phosphate binders and dialysates (4).

$\mathrm{ABD}$ is characterized by marked reduction of cell activity within the bone, both of osteoclasts and osteoblasts without excess osteoid accumulation (5), commonly seen in dialysis patients, and those with diabetes mellitus (6). The underpinning pathogenesis is skeletal resistance to parathyroid hormone (PTH) or iatrogenic PTH suppression. Over-suppressed PTH may result from overzealous use of calcium containing phosphate binders and/or use of vitamin D analogues (7). Although PTH levels may be above the upper limit of the normal reference range, patients with $\mathrm{ABD}$ frequently have skeletal resistance to the actions of $\mathrm{PTH}$. This is thought to be secondary to down regulation of PTH receptors on osteoblasts following chronically high PTH levels (8). Furthermore, down regulation of calcium sensing receptors 
on the parathyroid glands, diminishes their responsiveness to hypocalcaemia and reduces PTH pulsatility, a crucial factor in its anabolic actions on bone (8). Thus, the target range for PTH values for patients on dialysis is 2-9 times the upper limit of the normal reference range allowing for skeletal resistance(3).

Several other factors may contribute to the development of ABD. Patients with diabetes mellitus (DM) have higher levels of advanced glycation end products (AGEs), products of non-enzymatic glycation and oxidation of proteins and lipids, that disrupt skeletal collagen compromising bone integrity and strength $(9,10)$. Metabolic acidosis, which results in dissolution of bone mineral that is used as an acid buffer, low levels of bone morphogenic protein 7 (BMP-7), a protein expressed by the kidney that induces osteoblast differentiation, vitamin $\mathrm{K}$ deficiency and malnutrition and have also been implicated in the development of ABD (11).

No diagnostic biochemical markers confidently confirm the diagnosis of ABD, however, PTH levels consistently four to six times the upper limit of normal and an elevated ALP level would make the diagnosis unlikely (2).

Osteitis fibrosa cystica characterises high turnover bone disease resulting from the development of secondary hyperparathyroidism (SHPT). Phosphate retention, vitamin D deficiency and reduced 1-alpha hydroxylase activity with declining renal function predispose to SHPT (12). The compensatory rise in PTH is initially appropriate, increasing renal phosphate excretion and intestinal calcium absorption, stimulating bone reabsorption and increasing the activity of 1-alpha hydroxylase to correct developing hypocalcaemia (11). 
More recently, fibroblast growth factor-23 (FGF-23) has also been recognized to play an important role in this cascade. FGF-23 is a phosphaturic hormone secreted by osteocytes rising early in the development of $\mathrm{CKD}$ in response to phosphate retention. It acts on the sodium-phosphate transporters in the renal tubules to promote phosphaturia, inhibits the action of 1-alpha hydroxylase further reducing 1, 25-hydroxy-vitamin D levels, with additive effect of potentiating SHPT (13). Prolonged stimulation of the parathyroid glands may lead to tertiary hyperparathyroidism as a result of parathyroid tissue hyperplasia and down regulation of the calcium sensing and vitamin D receptors (14). This is a state of autonomously functioning parathyroid glands without appropriate responsiveness to plasma calcium concentrations. High levels of PTH continually stimulate bone turnover manifested by highly active osteoclasts and osteoblasts. The consequence is progressive resorption, predominately of cortical bone, that becomes increasingly weak with a predisposition for fracture (7).

The patient presented in this case exhibited many risk factors for the development of ABD. Long standing DM, chronically low PTH levels and 5 years of dialysis therapy are primary causative factors. High bone turnover disease was an unlikely diagnosis given low/normal PTH levels for many years prior.

Hypogonadism is reported in one-third to one-half of men with pre-dialysis $\mathrm{CKD}$, increasing to a prevalence of $50 \%$ to $75 \%$ in dialysis cohorts (15). There is a strong association between low testosterone, loss of BMD and fractures in men without CKD (16). Similarly in women, oestrogen deficiency is a known risk factor in the general population contributing to fragility fractures (17). Although the potential effects of hypogonadism on bone quality in patients with CKD-MBD were recognized by the KDIGO working group during the 2015 summit 
(18), the lack of clinical research examining this relationship did not allow for commentary regarding screening or treatment in the 2017 guidelines. Thus, the contribution of hypogonadism to fracture risk in patients with CKD or those on dialysis remains unclear.

Immunosuppressant medications, most notably glucocorticoids (GCs) also accelerate the risk for metabolic bone disorders, mainly osteoporosis. The commonly used loop diuretics in CKD can contribute to hypercalciuria and negative calcium balance, a further risk factor for defective mineralization (19). Importantly, ABD, SHPT, osteomalacia and other contributory bone abnormalities are not discrete entities, and patients frequently have mixed bone disease with features of both high and low turnover bone disorders (11). The type of bone disease that may occur in an individual may change over time and is dependent on the stage of CKD. SHPT and high turnover bone disease is typically observed early with the risk of low bone turnover disease increasing with progressive renal dysfunction, and particularly common in those on long-term dialysis. Furthermore, age-related osteoporosis becomes an increasing participant in the underling bone abnormalities in patients with CKD (20). Irrespective of the underlying histological defect, patients with pre-dialysis and dialysis dependant CKD have an increased risk of fractures compared to age, gender and BMD matched controls (21).

\section{Diagnosis and Investigations}

Assessment of bone mineral density (BMD) is most commonly measured using DXA and is recommended as per the general population in CKD stages 1-3 in the absence of mineral derangements; where low BMD remains a strong risk for fracture (22). The World Health 
Organisation (WHO) defines osteoporosis by DXA derived T-scores of $\mathrm{d}-2.5$ or in the presence of a low trauma fracture (1). Osteoporosis is also defined mechanically as a reduction in bone strength (comprised of bone density and bone quality) that predisposes to fracture (23).

In CKD stages 4-5, BMD typically underestimates fracture risk (2), with the disparity between BMD and fracture risk reflecting altered bone quality (trabecular and cortical bone microarchitecture, bone turnover, mineralization and collagen structure) that is not captured by the two-dimensional areal measurement of primarily bone mass by DXA (24). Additionally, it is well known that vascular calcification of the aorta or osteophytic changes in the lumbar spine, both frequently present in patients with $\mathrm{CKD}$, can produce an artefactually higher lumbar spine BMD and DXA T-score $(25,26)$.

Despite these limitations, there have been four prospective studies demonstrating value in fracture prediction of BMD measured by DXA at the hip, lumbar spine and or radius in the later stages of CKD (27-29) and those receiving HD (30). In light of these new data, the 2017 KDIGO guidelines have updated their recommendations to include DXA screening for all stages of CKD if the results will impact management decisions (Table 3) (3).

Newer imaging techniques with high-resolution peripheral quantitative computed tomography CT (HRpQCT) or MRI can assess aspects of bone quality (trabecular and cortical bone microarchitecture) utilising three-dimensional images with voxel sizes as low as $60 \mu \mathrm{m}$ and thus may provide more accurate diagnoses of the predominant bone disorder (31). These and other investigational imaging modalities, such as the Trabecular Bone Score (TBS) or micro- 
indentation techniques, have shown encouraging results in improving fracture prediction in the general population but are yet to be validated in the setting of CKD and not yet widely available.

Bone biopsy remains the most accurate tool for diagnosing metabolic bone disease in $\mathrm{CKD}$, allowing for the histomorphometric assessment of bone quality, including bone volume, mineralization and dynamic parameters of bone turnover.

In Australia bone biopsies are rarely performed to delineate the underlying bone disorder. When undertaken bone is biopsied from the iliac crest under local anaesthetic following preparation with two doses orally administered tetracycline 10-14 days apart which provides fluorescent labelling at two time points and thus the calculation of kinetic indices of bone turnover. The bone fragment obtained must contain trabecular and cortical bone and is embedded without de-calcification prior to analysis. Despite being the gold standard for diagnosing the underlying pathology in CKD-MBD (known as renal osteodystrophy (ROD)), it is performed in few specialised centres and its processing and analysis require significant expertise and thus is seldom performed in routine clinical practice. It is also limited by its ability to provide a measure of bone quality at a single site, and studies have shown significant discrepancies in the underlying ROD when samples have been concomitantly taken from the iliac crest, lumbar vertebra and proximal tibia $(32,33)$. Furthermore, two or more bone biopsies are required to assess response to therapy and no studies have demonstrated bone biopsy findings provide fracture prediction. The initial 2009 KDIGO guidelines necessitated a bone biopsy in patients with CKD-MBD prior to consideration of anti-resorptive therapy given theoretical concerns of inducing or worsening $\mathrm{ABD}$ in patients 
with already low bone turnover states. However, with no definitive evidence to suggest antiresorptive therapy induces $\mathrm{ABD}$, increasing post-hoc analyses of major osteoporosis trials and anecdotal clinical experience for the safety and efficacy of anti-resorptives and other osteoporosis treatments in patients with CKD (34-36), withholding treatment in the absence of a bone biopsy is no longer supported by the 2017 KDIGO clinical guidelines (Table 3) (3).

Bone turnover markers may be a useful adjunct to assessing metabolic bone disease in the general population; however, their utility is blunted in the context of CKD. The bone resorptive marker CTX is dependent on glomerular filtration for excretion and accumulates in patients with $\mathrm{CKD}$, and may be misleadingly elevated. Procollagen type $1 \mathrm{~N}$-terminal propeptide (P1NP) and bone specific alkaline phosphatase (BSAP), markers of bone formation, are not renally excreted and thus may be more reliable markers of bone turnover. Furthermore, concomitant GCs use for patients' primary renal disease may also affect bone turnover markers, especially in the early phase of GC therapy, most commonly reducing bone formation markers and increasing bone resorption markers (37-39). Although there is a paucity of longitudinal data correlating bone turnover markers with incident fractures, there are small cross-sectional studies correlating PTH and BSAP levels with their underlying bone histomorphometry in patients with $\operatorname{CKD}(6,40)$. The conclusion from these studies, and recommendations adopted by the KDIGO are that PTH levels consistently above $450 \mathrm{pg} / \mathrm{ml}$ (multiple by 0.105 to covert to pnmol/L) are unlikely to be associated with the presence of ABD.

More novel markers of bone activity, including the bone resorptive marker tartrate-resistant acid phosphatase (TRAP5b), FGF-23, and the osteocyte-derived glycoprotein, sclerostin, are 
currently being investigated for their utility in predicting fracture risk, but yet to be validated for clinical use.

\section{$\underline{C K D-M B D}$ management}

In all patients, non-pharmacological interventions to improve bone health and reduce fracture risk (eg. reducing falls) should always be offered. Weight bearing exercises and physiotherapy are an important part of primary and secondary fracture prevention, enhancing muscle strength and function and may reduce falls (41). Correcting cholecalciferol deficiency may also be important to maintain and improve bone and muscle health. As observed in the case, consideration should be given to peripheral neuropathy and proximal myopathy, and other risk factors for falls, and be managed appropriately.

\section{Phosphate binders}

Although the target phosphate level remains controversial, recommendations are to maintain levels towards the normal range with the use and up-titration of calcium or non-calcium based phosphate binders (such as lanthanum or sevelamer) and avoiding the long-term use of aluminium-containing phosphate binders. The revised guidelines stress that therapeutic decisions should be based according to the trend in levels rather than single measurements. Caution should be observed not to overly supplement calcium due to concerns of increasing vascular calcification and cardiovascular morbidity (42).

\section{Vitamin D and their analogues}


Vitamin D (cholecalciferol) supplementation can partially limit PTH elevations in patients with CKD (43), but few studies have examined the benefits of supplementation on bone outcomes. Active vitamin D analogues (1,25 di-hydroxycholecalciferol) such as calcitriol available in Australia (paricalcitol available in USA), may be considered if hyperparathyroidism persists after phosphate levels are controlled. Doses are up-titrated aiming for the KDIGO's recommended PTH value 2-9 times the upper limit of the reference range, owing to accumulation of c-terminal PTH fragments and PTH resistance of uraemic bone $(2,8)$. The PRIMO trial randomized 227 patients with CKD stage $3 \mathrm{a}-4$ to receive paricalcitol or placebo, (44) with secondary end points showing a significant reduction of PTH levels to $30 \%$ of baseline in the paricalcitol group versus $16.5 \%$ reduction in the placebo group $(\mathrm{p}<0.001)$. This was however, at the expense of significant increases in serum calcium and phosphate. Notably, these data are derived from post-hoc analyses as the primary outcomes were cardiovascular, and furthermore the short 12-month follow-up does not allow for adequate evaluation on fracture rates. Although their use has been shown to reduce PTH levels, the optimal target level of PTH for bone outcomes remains to be determined for patients with pre-dialysis and dialysis dependant $\mathrm{CKD}$, and there have been no studies adequately powered to show benefit in clinical outcomes such as fractures (45).

\section{$\underline{\text { Calcimimetics }}$}

Cinacalcet is a calcimimetic that reduces circulating PTH by binding to the calcium sensing receptor on the parathyroid glands, reducing the release of PTH. It is primarily used in patients with CKD to control SHPT, but its effects on BMD and fracture reduction efficacy have been debated. A one-year cohort study of 25 haemodialysis patients with 
hyperparathyroidism showed improvement of femoral neck BMD by $7.3 \%$ in patients receiving cinacalcet compared to a $6.2 \%$ decline in the control group (46), whilst other studies including a Cochrane systematic review have shown no benefit (47). Recent extrapolation of data used for the EVOLVE trial (48), where cinacalcet was compared to placebo in 3883 haemodialysis patients with SHPT, showed a reduction in PTH levels but no significant difference in fracture rates in unadjusted analysis, however there was a significant reduction after adjustment for baseline characteristics. (49).

Despite the lack of clear evidence or consensus amongst the KDIGO workgroup, the use of calcimimetics, calcitriol, vitamin $\mathrm{D}$ analogues or their combination in patients receiving dialysis requiring PTH lowering therapy continue to be recommended for patients receiving dialysis in the 2017 guidelines and are all are considered acceptable first line agents. Similar to the 2009 guidelines, the 2017 guidelines do not routinely recommend the use of these agents in patients with pre-dialysis CKD stage 4-5 except in cases of severe and progressive hyperparathyroidism (3). Of note, the use of cinacalcet in Australia is limited to private prescriptions given it was removed from subsidisation on the Pharmaceutical Benefits Scheme (PBS) in August 2015.

\section{Bisphosphonates}

Bisphosphonates are the most commonly used medication for management of osteoporosis in the general population. They are analogues of inorganic pyrophosphate which adsorb to the surface of bone hydroxyapatite and interfere with osteoclast-mediated bone resorption. 50$80 \%$ of bisphosphonates are taken up by bone and $20-50 \%$ renally excreted without prior 
metabolism (50). Most clinical trials analysing their efficacy in fracture reduction have excluded patients with significant renal impairment $(36,51,52)$ and there are limited clinical studies of bisphosphonate use in patients with CKD stages 4-5. Additionally, the use of bisphosphonates has also been associated with direct nephrotoxicity and in general they have been contraindicated in patients with an eGFR $<30 \mathrm{mls} / \mathrm{min}$. Nevertheless, there is growing evidence from post hoc analyses of data from the major trials of bisphosphates including risedronate (36) and alendronate (51), that have shown improvements in BMD in postmenopausal women with CKD stage 3-4 without increased renal adverse events. Of note however, these patients did not have perturbations in mineral metabolites. Trials in dialysis patients are equally sparse, although one randomized control study treated haemodialysis patients with 6 months of alendronate, and demonstrated stable hip BMD compared to placebo, but fracture outcomes were not reported (53). There is a theoretical concern however, that bisphosphonate administration in patients with $\mathrm{ABD}$ may exacerbate the underlying low activity metabolic abnormalities, further suppressing bone remodelling (50), but no studies have confirmed this hypothesis. With the current body of evidence, antiresorptive therapy with bisphosphonates in CKD stages 1-3 is recommended according to osteoporosis guidelines in the general population if there are no biochemical derangements (36). In CKD stage 4-5 treatment may also be considered, weighing an individual's benefit risk profile, based on biochemical disturbances, BMD, previous fracture history with consideration of an accurate diagnosis by bone biopsy (3).

\section{$\underline{\text { Denosumab }}$}


Denosumab is a fully humanized monoclonal antibody to the receptor activator of nuclear factor Kappa-B Ligand (RANKL) that inhibits osteoclast formation and functions in a dose dependant manner. It undergoes hepatic metabolism and renal function does not have a significant effect on its pharmacokinetic or pharmacodynamic properties (54). Although its safety and fracture reduction efficacy in CKD stage 4-5 has not been thoroughly evaluated, post hoc analyses of data from the FREEDOM trial (Fracture Reduction Evaluation of Denosumab in Osteoporosis every 6 Months) (54), demonstrated beneficial treatment outcomes with improvements in BMD and reduced risk of fracture amongst patients with stage 1-4 CKD (35). There were no patients with CKD stage 5 enrolled in the trial. As with bisphosphonates, there are concerns regarding the potential to worsen metabolic abnormalities in the presence of $\mathrm{ABD}$ due to its potent anti-resorptive properties. Concerningly, however, precipitating profound and prolonged hypocalcaemia resulting in seizures, cardiac arrhythmias and laryngospasm, post-denosumab administration in patients with CKD have been reported (55-58). Although there are no standardised and proven clinical recommendations to prevent this complication, evidence from small studies and expert opinion have recommended adequate vitamin $\mathrm{D}$ stores prior to the commencement of denosumab, with careful monitoring and supplementation of calcium as required post-dose, especially within the first few weeks following its administration (58-61). Anecdotally, some centres now avoid the use of denosumab in patients with CKD 4-5. Thus, although its nonrenal pharmacokinetics are appealing for use in $\mathrm{CKD}$, its role is yet to be fully defined for these patients, and risk of hypocalcaemia in patients with CKD remains a concern.

\section{$\underline{\text { Teriparatide }}$}


Teriparatide is a PTH analogue that directly stimulates osteoblastic bone formation, yielding anabolic benefits when given in cyclical doses to patients with osteoporosis. It improves BMD and reduces fractures in post-menopausal women with severe osteoporosis (62). In post hoc analyses of post-menopausal women with stage $3 \mathrm{CKD}$, it was shown have similar increments in P1NP and BMD compared to women with normal renal function, but at the cost of higher rates of hypercalcaemia and hyperuricaemia in the lower creatinine clearance group (62). Despite its fracture efficacy, studies of teriparatide in patients without CKD have demonstrated increased cortical thinning and cortical porosity, and thus its use may augment these abnormalities in patients with CKD-MBD with already high baseline PTH and should be avoided in such patients. Teriparatide has been proposed as a potential therapeutic intervention in patients with $\mathrm{CKD}$ and $\mathrm{ABD}$, with the conceivable mechanism of activating inactive osteoclasts and osteoblasts. There have been case reports and small trials $(\mathrm{n}<10$ patients) in haemodialysis patients with biopsy confirmed ABD with benefits in BMD following teriparatide administration (63-65). However, given the limited data evaluating its effect on $\mathrm{BMD}$, no evidence for fracture risk reduction and undefined safety profile, its use remains undefined in patients with $\mathrm{CKD}-\mathrm{MBD}$ and $\mathrm{ABD}$.

\section{$\underline{\text { Renal transplantation }}$}

Successful renal transplantation reverses many metabolic and mineral derangements that occur in $\mathrm{CKD}$, with ensuing improvements in morbidity and mortality compared to dialysis (66). Renal transplant recipients, however, remain at high risk of fracture, with a fourfold increased risk over the general population and hip fracture rates exceeding those on dialysis (67, 68). Hyperparathyroidism, in the absence of autonomous function, usually improves, 
within the first one to two years. Persistently elevated PTH levels are seen in up to $45 \%$ of patients due to parathyroid hyperplasia or adenomas (69) and correlate with significant bone loss at the hip (70) and levels $>130 \mathrm{pg} / \mathrm{ml} 3$ months post-transplantation are associated with a significant increased risk for incident fracture (71). Serum calcium levels usually normalise, however in the face of persistent hyperparathyroidism and improved 1, 25 hydroxy-vitamin D production, elevated levels may become exacerbated and potentially worsen. Hypophosphataemia is common early post-transplant due to elevated FGF-23 and PTH levels and use of calcineurin inhibitors (72). FGF-23 levels decline following transplantation, and tend to normalise by 12 months, and together with reductions in PTH levels, there is concurrent stabilisation of phosphate levels (72). Persistent hypophosphataemia has been reported in the presence of ongoing elevated PTH levels $(72,73)$ and there has been a report of increased fracture rates in renal transplant recipients with lower serum phosphate levels (74). However, the long term consequences of low serum phosphate post-transplantation on bone metabolism and fracture, remain to be established (72).

Low bone turnover states may improve many years following transplantation with restoration of PTH levels, but ABD remains common (75). Bone disease in renal transplant recipients may reflect pre-existing, persistent or de novo mineral and bone disturbances but commonly also results in the development of osteoporosis, as a consequence of advancing age and GCs immunosuppression (76). Early studies showed rapid bone loss in the first 6-12 months posttransplantation, with $4-10 \%$ declines in BMD at 6 months (77). More recent data from prospective trials suggest BMD losses are lower at $0.1-5.7 \%$. This has been attributed to earlier withdrawal of GCs, increased use of vitamin D analogues and anti-resorptive agents in 
the post-transplant period and potentially better pre-transplantation management of CKD$\operatorname{MBD}(78)$.

Differentiating between high and low turnover bone disease or osteoporosis also remains challenging post-renal transplantation whereby biochemical and DXA imaging parameters are not consistent predictors of the underlying bone disease or fracture. Although the predictive value of DXA in these patients is not widely acknowledged, the KDIGO now recommends DXA screening in transplant patients with eGFR $>30 \mathrm{mls} / \mathrm{min} / 1.73 \mathrm{~m}^{2}(3)$, following the recent studies demonstrating its value in fracture prediction $(27-30,79,80)$.

\section{THE CASE}

\section{Patient management}

This case exemplifies the difficulties in the diagnosis and management of patients with fragility fractures in the context of CKD. The patient reported had multiple risk factors for fragility fracture, including long standing diabetes mellitus and $\mathrm{CKD}$, chronic haemodialysis, and PTH levels that were consistently low prior to renal transplantation consequent to the use of phosphate binders and calcitriol. The patient's biochemical profile of a normal ALP and persistent low normal PTH values make a diagnosis of osteitis fibrosa cystica unlikely. The acute elevation in PTH immediately prior to his transplant was secondary to cessation of calcitriol and phosphate binders and is not characteristic of the chronic elevation in PTH seen in secondary or tertiary hyperparathyroidism. Immunosuppressant agents used, most notably 
GCs, are likely culprits that further impaired his bone microarchitecture and bone strength post-transplant. The DXA scan revealed a BMD in the osteoporotic range at the femoral neck and osteopenic range at the lumbar spine, and this discrepancy between femoral neck and lumbar spine BMD is commonly seen in patients with CKD-MBD due to overlying aortic calcification and/or osteophytic changes at the lumbar spine.

This patient was a high risk for future fractures and treatment was deemed necessary, however, given the concerns about anti-resorptive agents in patients with a biochemical profile suggestive of low bone turnover, and given the patients presentation preceded the 2017 KDIGO update, a bone biopsy was considered essential prior to commencing antiresorptive treatment and thus performed. The bone biopsy, utilising double labelled doxycycline, showed sparse inactive trabecular bone with no observable mineralization front, nor osteoclasts or osteoblasts (Figure 1a and $1 \mathrm{~b}$ ). The toluidine blue stain revealed only a very small rim of osteoid present with less than $1 \%$ coverage of the bone surface (Figure 1c). The Congo red stain for amyloid was negative and there were no features of aluminium deposition (images not shown). Collectively, these features were consistent with a diagnosis of $\mathrm{ABD}$.

He was treated with cholecalciferol replacement, with an ensuing reduction in his PTH levels, a result of replenished cholecalciferol status and improved renal function, and repeat testosterone levels were within normal limits. He was advised to increase his dietary calcium intake and continue physiotherapy with weight bearing exercises. Teriparatide treatment was a potential avenue but given the paucity of evidence to support beneficial effects in ABD and its unclear safety profile in patients with CKD-MBD, it was not pursued. 


\section{$\underline{\text { Conclusion }}$}

Patients with CKD-MBD are at high risk of fracture, cardiovascular disease and have increased overall mortality. Although our understanding of the pathophysiological mechanisms underpinning these bone and mineral disturbances has progressed, development of accurate screening tools has lagged. Given the recent validation of DXA to predict fracture across all stages of CKD including those receiving dialysis, in the absence of a bone biopsy, the combination of low BMD on DXA and biochemical markers coupled with clinical risk factors remain our most powerful indicators of fracture risk in these patients. Management of bone health in patients with stages 1-3 CKD without mineral abnormalities should be equivalent to the general population, and in later stages of CKD focuses on controlling SHPT without over suppression of PTH, but optimal target levels of PTH, phosphate and vitamin D for bone health remain unclear. Despite increasing evidence and clinical experience for the efficacy and safety of bisphosphonates and teriparatide in patients with CKD and treatment supported by the 2017 KDIGO guidelines, the use of bisphosphates or teriparatide in patients with an eGFR $<30 \mathrm{mls} / \mathrm{min}$ (CKD 4 and beyond) is not currently approved in Australia. Although denosumab is registered for use in all stages of CKD with efficacy in BMD improvements, no studies have yet evaluated fracture data and the increasing concerns regarding its safety in patients with moderate and severe CKD has brought caution to its routine use in these patients.

The updated 2017 KDIGO guidelines for the diagnosis, evaluation, prevention and treatment of CKD-MBD reflect the current evidence pool, with major updates influencing bone health in the diagnostic usefulness of BMD testing by DXA, regression of mandatory bone biopsy 
requirements and suggestion of individualised treatment strategies according to patients' clinical, biochemical and BMD risk factors. However, significant evidence gaps remain and given the high fracture risk, associated increased morbidity, mortality and economic burden of patients with CKD-MBD, there is an urgent need for additional research to further define pathophysiological mechanisms, validate accessible diagnostic tools and develop evidencebased treatment strategies for these patients.

Acknowledgment: The patient presented in this case consented to release of his de-identified clinical information for this publication. 


\section{References}

1. Kanis JA. Assessment of fracture risk and its application to screening for postmenopausal osteoporosis: synopsis of a WHO report. WHO Study Group. Osteoporos Int. 1994;4(6):368-81. PubMed PMID: 7696835.

2. Group KDIGOKC-MW. KDIGO clinical practice guideline for the diagnosis, evaluation, prevention, and treatment of Chronic Kidney Disease-Mineral and Bone Disorder (CKD-MBD). Kidney Int Suppl. 2009(113):S1-130. doi: 10.1038/ki.2009.188. PubMed PMID: 19644521.

3. Ketteler M, Block GA, Evenepoel P, Fukagawa M, Herzog CA, McCann L, et al. Executive summary of the 2017 KDIGO Chronic Kidney Disease-Mineral and Bone Disorder (CKD-MBD) Guideline Update: what's changed and why it matters. Kidney Int. 2017;92(1):26-36. Epub 2017/06/26. doi: 10.1016/j.kint.2017.04.006. PubMed PMID: 28646995.

4. Gonzalez EA, Martin KJ. Aluminum and renal osteodystrophy A diminishing clinical problem. Trends Endocrinol Metab. 1992;3(10):371-5. PubMed PMID: 18407124.

5. Cannata-Andía JB, Rodriguez García M, Gómez Alonso C. Osteoporosis and adynamic bone in chronic kidney disease. J Nephrol. 2013;26(1):73-80. doi: 10.5301/jn.5000212. PubMed PMID: 23023723.

6. Hutchison AJ, Whitehouse RW, Boulton HF, Adams JE, Mawer EB, Freemont TJ, et al. Correlation of bone histology with parathyroid hormone, vitamin D3, and radiology in end-stage renal disease. Kidney International. 1993;44(5):1071-7. doi: http://dx.doi.org/10.1038/ki.1993.350.

7. Arnaud CD. Hyperparathyroidism and renal failure. Kidney Int. 1973;4(2):89-95. PubMed PMID: 4598144.

8. Picton ML, Moore PR, Mawer EB, Houghton D, Freemont AJ, Hutchison AJ, et al. Down-regulation of human osteoblast PTH/PTHrP receptor mRNA in end-stage renal failure. Kidney Int. 2000;58(4):1440-9. doi: 10.1046/j.1523-1755.2000.00306.x. PubMed PMID: 11012879.

9. Ahmed N, Thornalley PJ. Advanced glycation endproducts: what is their relevance to diabetic complications? Diabetes Obes Metab. 2007;9(3):233-45. doi: 10.1111/j.1463-1326.2006.00595.x. PubMed PMID: 17391149.

10. Wang X, Shen X, Li X, Agrawal CM. Age-related changes in the collagen network and toughness of bone. Bone. 2002;31(1):1-7. PubMed PMID: 12110404

11. Martin KJ, González EA. Metabolic Bone Disease in Chronic Kidney Disease. Journal of the American Society of Nephrology. 2007;18(3):875-85. doi: 10.1681/ASN.2006070771.

12. GOLDMAN R, BASSETT SH. Phosphorus excretion in renal failure. J Clin Invest. 1954;33(12):16238. doi: 10.1172/JCI103042. PubMed PMID: 13211818; PubMed Central PMCID: PMCPMC1072593.

13. Baia LC, Heilberg IP, Navis G, de Borst MH, investigators N. Phosphate and FGF-23 homeostasis after kidney transplantation. Nat Rev Nephrol. 2015;11(11):656-66. doi: 10.1038/nrneph.2015.153. PubMed PMID: 26416497.

14. Grzela T, Chudzinski W, Lasiecka Z, Niderla J, Wilczynski G, Gornicka B, et al. The calcium-sensing receptor and vitamin D receptor expression in tertiary hyperparathyroidism. Int J Mol Med. 2006;17(5):779-83. PubMed PMID: 16596260.

15. Carrero JJ, Stenvinkel P. The vulnerable man: impact of testosterone deficiency on the uraemic phenotype. Nephrol Dial Transplant. 2012;27(11):4030-41. doi: 10.1093/ndt/gfs383. PubMed PMID: 22962412.

16. Fink HA, Ewing SK, Ensrud KE, Barrett-Connor E, Taylor BC, Cauley JA, et al. Association of testosterone and estradiol deficiency with osteoporosis and rapid bone loss in older men. J Clin Endocrinol Metab. 2006;91(10):3908-15. doi: 10.1210/jc.2006-0173. PubMed PMID: 16849417.

17. Lobo RA. Hormone-replacement therapy: current thinking. Nature reviews Endocrinology. 2016. Epub 2016/10/08. doi: 10.1038/nrendo.2016.164. PubMed PMID: 27716751.

18. Ketteler M, Elder GJ, Evenepoel P, Ix JH, Jamal SA, Lafage-Proust MH, et al. Revisiting KDIGO clinical practice guideline on chronic kidney disease-mineral and bone disorder: a commentary from a Kidney Disease: Improving Global Outcomes controversies conference. Kidney Int. 2015;87(3):502-28. doi: 10.1038/ki.2014.425. PubMed PMID: 25651364.

19. Nickolas TL, Cremers S, Zhang A, Thomas V, Stein E, Cohen A, et al. Discriminants of prevalent fractures in chronic kidney disease. J Am Soc Nephrol. 2011;22(8):1560-72. doi: 10.1681/ASN.2010121275. PubMed PMID: 21784896; PubMed Central PMCID: PMCPMC3148711. 
20. Nickolas TL, McMahon DJ, Shane E. Relationship between moderate to severe kidney disease and hip fracture in the United States. Journal of the American Society of Nephrology. 2006;17(11):3223-32. doi:

10.1681/ASN.2005111194.

21. Ensrud KE. Fracture risk in CKD. Clin J Am Soc Nephrol. 2013;8(8):1282-3. doi:

10.2215/CJN.06300613. PubMed PMID: 23846461; PubMed Central PMCID: PMCPMC3731902.

22. Johnell O, Kanis JA, Oden A, Johansson H, De Laet C, Delmas P, et al. Predictive value of BMD for hip and other fractures. J Bone Miner Res. 2005;20(7):1185-94. doi: 10.1359/JBMR.050304. PubMed PMID: 15940371.

23. Osteoporosis prevention, diagnosis, and therapy. Jama. 2001;285(6):785-95. Epub 2001/02/15. PubMed PMID: 11176917.

24. Jassal SK, von Muhlen D, Barrett-Connor E. Measures of renal function, BMD, bone loss, and osteoporotic fracture in older adults: the Rancho Bernardo study. J Bone Miner Res. 2007;22(2):203-10. doi: 10.1359/jbmr.061014. PubMed PMID: 17059370; PubMed Central PMCID: PMCPMC2895929.

25. Drinka PJ, DeSmet AA, Bauwens SF, Rogot A. The effect of overlying calcification on lumbar bone densitometry. Calcif Tissue Int. 1992;50(6):507-10. Epub 1992/06/01. PubMed PMID: 1525705.

26. Chau K, Martinez G, Elder GJ. Vascular calcification in patients undergoing kidney and simultaneous pancreas-kidney transplantation. Nephrology (Carlton). 2014;19(5):275-81. Epub 2014/02/11. doi:

10.1111/nep.12212. PubMed PMID: 24506475.

27. Yenchek RH, Ix JH, Shlipak MG, Bauer DC, Rianon NJ, Kritchevsky SB, et al. Bone mineral density and fracture risk in older individuals with CKD. Clin J Am Soc Nephrol. 2012;7(7):1130-6. doi:

10.2215/CJN.12871211. PubMed PMID: 22516286; PubMed Central PMCID: PMCPMC3386677.

28. Naylor KL, Garg AX, Zou G, Langsetmo L, Leslie WD, Fraser LA, et al. Comparison of fracture risk prediction among individuals with reduced and normal kidney function. Clin J Am Soc Nephrol.

2015;10(4):646-53. doi: 10.2215/CJN.06040614. PubMed PMID: 25655423; PubMed Central PMCID: PMCPMC4386249.

29. West SL, Lok CE, Langsetmo L, Cheung AM, Szabo E, Pearce D, et al. Bone mineral density predicts fractures in chronic kidney disease. J Bone Miner Res. 2015;30(5):913-9. doi: 10.1002/jbmr.2406. PubMed PMID: 25400209.

30. Iimori S, Mori Y, Akita W, Kuyama T, Takada S, Asai T, et al. Diagnostic usefulness of bone mineral density and biochemical markers of bone turnover in predicting fracture in CKD stage 5D patients--a singlecenter cohort study. Nephrol Dial Transplant. 2012;27(1):345-51. doi: 10.1093/ndt/gfr317. PubMed PMID: 21652550.

31. Nickolas TL, Stein EM, Dworakowski E, Nishiyama KK, Komandah-Kosseh M, Zhang CA, et al. Rapid cortical bone loss in patients with chronic kidney disease. J Bone Miner Res. 2013;28(8):1811-20. doi: 10.1002/jbmr.1916. PubMed PMID: 23456850; PubMed Central PMCID: PMCPMC3720694.

32. Hiller RG, Patecki M, Neunaber C, Reifenrath J, Kielstein JT, Kielstein H. A comparative study of bone biopsies from the iliac crest, the tibial bone, and the lumbar spine. BMC Nephrol. 2017;18(1):134. Epub 2017/04/15. doi: 10.1186/s12882-017-0550-5. PubMed PMID: 28407760; PubMed Central PMCID: PMCPMC5391565.

33. Torres PU, Bover J, Mazzaferro S, de Vernejoul MC, Cohen-Solal M. When, how, and why a bone biopsy should be performed in patients with chronic kidney disease. Semin Nephrol. 2014;34(6):612-25. Epub 2014/12/17. doi: 10.1016/j.semnephrol.2014.09.004. PubMed PMID: 25498380.

34. Wilson LM, Rebholz CM, Jirru E, Liu MC, Zhang A, Gayleard J, et al. Benefits and harms of osteoporosis medications in patients with chronic kidney disease: A systematic review and meta-analysis. Annals of Internal Medicine. 2017;166(9):649-58. doi: 10.7326/M16-2752.

35. Jamal SA, Ljunggren O, Stehman-Breen C, Cummings SR, McClung MR, Goemaere S, et al. Effects of denosumab on fracture and bone mineral density by level of kidney function. J Bone Miner Res.

2011;26(8):1829-35. doi: 10.1002/jbmr.403. PubMed PMID: 21491487.

36. Miller PD, Roux C, Boonen S, Barton IP, Dunlap LE, Burgio DE. Safety and efficacy of risedronate in patients with age-related reduced renal function as estimated by the Cockcroft and Gault method: a pooled analysis of nine clinical trials. J Bone Miner Res. 2005;20(12):2105-15. doi: 10.1359/JBMR.050817. PubMed PMID: 16294264. 
37. Morrison D, Ali NJ, Routledge PA, Capewell S. Bone turnover during short course prednisolone treatment in patients with chronic obstructive airways disease. Thorax. 1992;47(6):418-20. Epub 1992/06/01. PubMed PMID: 1496499; PubMed Central PMCID: PMCPMC463804.

38. Paglia F, Dionisi S, De Geronimo S, Rosso R, Romagnoli E, Raejentroph N, et al. Biomarkers of Bone Turnover after a Short Period of Steroid Therapy in Elderly Men. Clinical Chemistry. 2001;47(7):1314.

39. Manolagas SC. Birth and death of bone cells: basic regulatory mechanisms and implications for the pathogenesis and treatment of osteoporosis. Endocr Rev. 2000;21(2):115-37. Epub 2000/04/27. doi: 10.1210/edrv.21.2.0395. PubMed PMID: 10782361.

40. Lehmann G, Ott U, Kaemmerer D, Schuetze J, Wolf G. Bone histomorphometry and biochemical markers of bone turnover in patients with chronic kidney disease Stages 3 - 5. Clin Nephrol. 2008;70(4):296305. PubMed PMID: 18826854.

41. Ebeling PR, Daly RM, Kerr DA, Kimlin MG. Building healthy bones throughout life: an evidenceinformed strategy to prevent osteoporosis in Australia. Med J Aust. 2013;199(7 Suppl):S1. PubMed PMID: 25370432.

42. Bolland MJ, Avenell A, Baron JA, Grey A, MacLennan GS, Gamble GD, et al. Effect of calcium supplements on risk of myocardial infarction and cardiovascular events: meta-analysis. BMJ. 2010;341:c3691. PubMed PMID: 20671013; PubMed Central PMCID: PMCPMC2912459.

43. Kandula P, Dobre M, Schold JD, Schreiber MJ, Mehrotra R, Navaneethan SD. Vitamin D Supplementation in Chronic Kidney Disease: A Systematic Review and Meta-Analysis of Observational Studies and Randomized Controlled Trials. Clinical Journal of the American Society of Nephrology : CJASN. 2011;6(1):50-62. doi: 10.2215/CJN.03940510. PubMed PMID: PMC3022248.

44. Thadhani R, Appelbaum E, Pritchett Y, Chang Y, Wenger J, Tamez H, et al. Vitamin D therapy and cardiac structure and function in patients with chronic kidney disease: the PRIMO randomized controlled trial. JAMA. 2012;307(7):674-84. doi: 10.1001/jama.2012.120. PubMed PMID: 22337679.

45. Palmer SC, McGregor DO, Craig JC, Elder G, Macaskill P, Strippoli GF. Vitamin D compounds for people with chronic kidney disease requiring dialysis. The Cochrane database of systematic reviews. 2009(4):Cd005633. Epub 2009/10/13. doi: 10.1002/14651858.CD005633.pub2. PubMed PMID: 19821349. 46. Tsuruta Y, Okano K, Kikuchi K, Tsuruta Y, Akiba T, Nitta K. Effects of cinacalcet on bone mineral density and bone markers in hemodialysis patients with secondary hyperparathyroidism. Clin Exp Nephrol. 2013;17(1):120-6. Epub 2012/07/27. doi: 10.1007/s10157-012-0665-8. PubMed PMID: 22833360.

47. Ballinger AE, Palmer SC, Nistor I, Craig JC, Strippoli GF. Calcimimetics for secondary hyperparathyroidism in chronic kidney disease patients. The Cochrane database of systematic reviews. 2014(12):Cd006254. Epub 2014/12/10. doi: 10.1002/14651858.CD006254.pub2. PubMed PMID: 25490118. 48. Chertow GM, Block GA, Correa-Rotter R, Drüeke TB, Floege J, Goodman WG, et al. Effect of cinacalcet on cardiovascular disease in patients undergoing dialysis. N Engl J Med. 2012;367(26):2482-94. doi: 10.1056/NEJMoa1205624. PubMed PMID: 23121374.

49. Moe SM, Abdalla S, Chertow GM, Parfrey PS, Block GA, Correa-Rotter R, et al. Effects of Cinacalcet on Fracture Events in Patients Receiving Hemodialysis: The EVOLVE Trial. J Am Soc Nephrol. 2015;26(6):1466-75. doi: 10.1681/ASN.2014040414. PubMed PMID: 25505257; PubMed Central PMCID: PMCPMC4446874.

50. Fleisch H. Bisphosphonates: mechanisms of action. Endocr Rev. 1998;19(1):80-100. doi: 10.1210/edrv.19.1.0325. PubMed PMID: 9494781.

51. Jamal SA, Bauer DC, Ensrud KE, Cauley JA, Hochberg M, Ishani A, et al. Alendronate treatment in women with normal to severely impaired renal function: an analysis of the fracture intervention trial. J Bone Miner Res. 2007;22(4):503-8. doi: 10.1359/jbmr.070112. PubMed PMID: 17243862.

52. Boonen S, Sellmeyer DE, Lippuner K, Orlov-Morozov A, Abrams K, Mesenbrink P, et al. Renal safety of annual zoledronic acid infusions in osteoporotic postmenopausal women. Kidney Int. 2008;74(5):641-8. doi: 10.1038/ki.2008.193. PubMed PMID: 18509324.

53. Wetmore JB, Benet LZ, Kleinstuck D, Frassetto L. Effects of short-term alendronate on bone mineral density in haemodialysis patients. Nephrology (Carlton). 2005;10(4):393-9. doi: 10.1111/j.14401797.2005.00436.x. PubMed PMID: 16109088. 
54. Cummings SR, San Martin J, McClung MR, Siris ES, Eastell R, Reid IR, et al. Denosumab for prevention of fractures in postmenopausal women with osteoporosis. N Engl J Med. 2009;361(8):756-65. doi: 10.1056/NEJMoa0809493. PubMed PMID: 19671655.

55. Okada N, Kawazoe K, Teraoka K, Kujime T, Abe M, Shinohara Y, et al. Identification of the risk factors associated with hypocalcemia induced by denosumab. Biol Pharm Bull. 2013;36(10):1622-6. PubMed PMID: 23934346.

56. Teng J, Abell S, Hicks RJ, Hofman MS, Sachithanandan N, McKelvie P, et al. Protracted hypocalcaemia following a single dose of denosumab in humoral hypercalcaemia of malignancy due to PTHrPsecreting neuroendocrine tumour. Clin Endocrinol (Oxf). 2014;81(6):940-2. doi: 10.1111/cen.12519. PubMed PMID: 24890549

57. Lambe G, Malvathu R, Thomas HM, Graves A. Hypocalcaemic tetany occurring post a single denosumab dose in a patient with stage 4 chronic kidney disease, followed by calcium- and calcitriol-induced hypercalcaemia. Nephrology (Carlton). 2015;20(8):583-4. Epub 2015/07/22. doi: 10.1111/nep.12432. PubMed PMID: 26194986.

58. Dave V, Chiang CY, Booth J, Mount PF. Hypocalcemia post denosumab in patients with chronic kidney disease stage 4-5. American Journal of Nephrology. 2015;41(2):129-37. doi: 10.1159/000380960. 59. Majeed SS, Wright D, Webber S. E64. Post-Denosumab Hypocalcaemia Monitoring in Renal Impairment. Rheumatology. 2015;54(suppl_1):i194-i5. doi: 10.1093/rheumatology/kev091.064.

60. Festuccia F, Jafari MT, Moioli A, Fofi C, Barberi S, Amendola S, et al. Safety and efficacy of denosumab in osteoporotic hemodialysed patients. J Nephrol. 2017;30(2):271-9. Epub 2016/07/11. doi: 10.1007/s40620-016-0334-1. PubMed PMID: 27394428.

61. Block GA, Bone HG, Fang L, Lee E, Padhi D. A single-dose study of denosumab in patients with various degrees of renal impairment. J Bone Miner Res. 2012;27(7):1471-9. Epub 2012/03/31. doi: 10.1002/jbmr.1613. PubMed PMID: 22461041; PubMed Central PMCID: PMCPMC3505375.

62. Miller PD, Schwartz EN, Chen P, Misurski DA, Krege JH. Teriparatide in postmenopausal women with osteoporosis and mild or moderate renal impairment. Osteoporos Int. 2007;18(1):59-68. doi: 10.1007/s00198006-0189-8. PubMed PMID: 17013567.

63. Cejka D, Kodras K, Bader T, Haas M. Treatment of Hemodialysis-Associated Adynamic Bone Disease with Teriparatide (PTH1-34): A Pilot Study. Kidney Blood Press Res. 2010;33(3):221-6. doi: 10.1159/000316708. PubMed PMID: 20588059.

64. Palcu P, Dion N, Ste-Marie LG, Goltzman D, Radziunas I, Miller PD, et al. Teriparatide and bone turnover and formation in a hemodialysis patient with low-turnover bone disease: A case report. American Journal of Kidney Diseases. 2015;65(6):933-6. doi: 10.1053/j.ajkd.2015.01.025.

65. Mitsopoulos E, Ginikopoulou E, Economidou D, Zanos S, Pateinakis P, Minasidis E, et al. Impact of long-term cinacalcet, ibandronate or teriparatide therapy on bone mineral density of hemodialysis patients: a pilot study. Am J Nephrol. 2012;36(3):238-44. Epub 2012/09/06. doi: 10.1159/000341864. PubMed PMID: 22948280

66. Laupacis A, Keown P, Pus N, Krueger H, Ferguson B, Wong C, et al. A study of the quality of life and cost-utility of renal transplantation. Kidney Int. 1996;50(1):235-42. PubMed PMID: 8807593.

67. Abbott KC, Oglesby RJ, Hypolite IO, Kirk AD, Ko CW, Welch PG, et al. Hospitalizations for fractures after renal transplantation in the United States. Ann Epidemiol. 2001;11(7):450-7. PubMed PMID: 11557176.

68. Ball AM, Gillen DL, Sherrard D, Weiss NS, Emerson SS, Seliger SL, et al. Risk of hip fracture among dialysis and renal transplant recipients. JAMA. 2002;288(23):3014-8. PubMed PMID: 12479766.

69. Lou I, Foley D, Odorico SK, Leverson G, Schneider DF, Sippel R, et al. How Well Does Renal Transplantation Cure Hyperparathyroidism? Ann Surg. 2015;262(4):653-9. doi: 10.1097/SLA.0000000000001431. PubMed PMID: 26366545; PubMed Central PMCID: PMCPMC4576689. 70. Akaberi S, Lindergård B, Simonsen O, Nyberg G. Impact of parathyroid hormone on bone density in long-term renal transplant patients with good graft function. Transplantation. 2006;82(6):749-52. doi: 10.1097/01.tp.0000230130.50451.78. PubMed PMID: 17006320.

71. Perrin P, Caillard S, Javier RM, Braun L, Heibel F, Borni-Duval C, et al. Persistent hyperparathyroidism is a major risk factor for fractures in the five years after kidney transplantation. Am $\mathrm{J}$ Transplant. 2013;13(10):2653-63. Epub 2013/09/17. doi: 10.1111/ajt.12425. PubMed PMID: 24034142. 
72. Wolf M, Weir MR, Kopyt N, Mannon RB, Von Visger J, Deng H, et al. A Prospective Cohort Study of Mineral Metabolism After Kidney Transplantation. Transplantation. 2016;100(1):184-93. doi:

10.1097/TP.0000000000000823. PubMed PMID: 26177089; PubMed Central PMCID: PMCPMC4683035.

73. Tomida K, Hamano T, Ichimaru N, Fujii N, Matsui I, Nonomura N, et al. Dialysis vintage and parathyroid hormone level, not fibroblast growth factor-23, determines chronic-phase phosphate wasting after renal transplantation. Bone. 2012;51(4):729-36. Epub 2012/07/17. doi: 10.1016/j.bone.2012.06.027. PubMed PMID: 22796419.

74. Aleksova J, Wong P, Mulley WR, Choy KW, McLachlan R, Ebeling PR, et al. Serum phosphorus levels and fracture following renal transplantation. Clin Endocrinol (Oxf). 2017;87(2):141-8. doi:

10.1111/cen.13363. PubMed PMID: 28449252.

75. Cruz EA, Lugon JR, Jorgetti V, Draibe SA, Carvalho AB. Histologic evolution of bone disease 6 months after successful kidney transplantation. Am J Kidney Dis. 2004;44(4):747-56. PubMed PMID: 15384027.

76. Elder G. Pathophysiology and recent advances in the management of renal osteodystrophy. J Bone Miner Res. 2002;17(12):2094-105. doi: 10.1359/jbmr.2002.17.12.2094. PubMed PMID: 12469904.

77. Julian BA, Laskow DA, Dubovsky J, Dubovsky EV, Curtis JJ, Quarles LD. Rapid loss of vertebral mineral density after renal transplantation. N Engl J Med. 1991;325(8):544-50. doi:

10.1056/NEJM199108223250804. PubMed PMID: 1857390.

78. Nikkel LE, Mohan S, Zhang A, McMahon DJ, Boutroy S, Dube G, et al. Reduced fracture risk with early corticosteroid withdrawal after kidney transplant. Am J Transplant. 2012;12(3):649-59. doi: 10.1111/j.1600-6143.2011.03872.x. PubMed PMID: 22151430; PubMed Central PMCID: PMCPMC4139036. 79. Akaberi S, Simonsen O, Lindergård B, Nyberg G. Can DXA predict fractures in renal transplant patients? Am J Transplant. 2008;8(12):2647-51. doi: 10.1111/j.1600-6143.2008.02423.x. PubMed PMID: 18853956.

80. Jiménez S, Marcén R, Vaamonde C, Caballero C, Fernández-Rodríguez A, Villafruela JJ, et al. Bone fractures and lumbar mineral density after renal transplantation. A long-term cross-sectional study. Clin Transplant. 2016;30(2):131-7. doi: 10.1111/ctr.12666. PubMed PMID: 26546290.

81. Burns PB, Rohrich RJ, Chung KC. The Levels of Evidence and their role in Evidence-Based Medicine. Plastic and reconstructive surgery. 2011;128(1):305-10. doi: 10.1097/PRS.0b013e318219c171. PubMed PMID: PMC3124652. 
Table 1: Patient's medication list

- Cholecalciferol 3000 IU daily

(Started 2 weeks before his appointment)

- Prednisolone $12.5 \mathrm{mg}$

- Mycophenolate

- Tacrolimus

- Dapsone

- Amphotericin lozenges

- Valganciclovir

- Novorapid TDS

- Glargine daily

- Atorvastatin
- Pregabalin

- Levodopa-carbidopa

- Amitriptyline

- Oxycodone

- Domperidone TDS

- Ranitidine

- Metoprolol

- Moxonidine

- Frusemide

- Hydrochlorothiazide

- Potassium chloride

- Magnesium 
Table 2: Patients Biochemical and metabolic bone profile

\begin{tabular}{|c|c|c|c|c|c|c|c|}
\hline & $\begin{array}{l}\text { 2-years pre- } \\
\text { transplant }\end{array}$ & $\begin{array}{l}1 \text {-year pre- } \\
\text { transplant }\end{array}$ & $\begin{array}{l}\text { Day of } \\
\text { transplant }\end{array}$ & \begin{tabular}{|l|}
2 weeks \\
post- \\
transplant
\end{tabular} & $\begin{array}{l}\text { Fracture } \\
\text { (5 weeks } \\
\text { post- } \\
\text { transplant) }\end{array}$ & $\begin{array}{l}3 \text { months } \\
\text { post- } \\
\text { transplant }\end{array}$ & $\begin{array}{l}6 \text { months } \\
\text { post- } \\
\text { transplant }\end{array}$ \\
\hline $\begin{array}{l}\text { Calcium } \\
(2.12-2.62 \\
\mathrm{mmol} / \mathrm{L})\end{array}$ & 2.41 & 2.31 & 2.06 & 2.37 & 2.3 & 2.53 & 2.52 \\
\hline $\begin{array}{l}\text { Phosphate } \\
(0.87-1.45 \\
\text { mmol/L) }\end{array}$ & 1.24 & 1.53 & 1.63 & 0.73 & 1.20 & 1.19 & 1.30 \\
\hline $\begin{array}{l}\text { ALP } \\
(55-120 \mathrm{U} / \mathrm{L})\end{array}$ & 115 & 109 & 87 & & & & 96 \\
\hline $\begin{array}{l}\text { Creatinine } \\
(64-104 \text { umol/L) }\end{array}$ & N/A & N/A & 628 & 167 & 177 & 93 & 137 \\
\hline $\begin{array}{l}\text { PTH } \\
(12-65 \mathrm{pg} / \mathrm{ml})\end{array}$ & 22.6 & 34.8 & 673 & 277 & 198 & 62 & \\
\hline $\begin{array}{l}25-\text { Vit D } \\
(75-150 \mathrm{nmol} / \mathrm{L})\end{array}$ & & & & & $<20$ & 65 & 126 \\
\hline C-telopeptide & & & & & & & 168 \\
\hline
\end{tabular}

This article is protected by copyright. All rights reserved. 


\begin{tabular}{|c|c|c|c|c|c|}
\hline$(<400 \mathrm{ng} / \mathrm{L})$ & & & & & \\
\hline $\begin{array}{l}\text { P1NP } \\
(14-80 \mathrm{ug} / \mathrm{L})\end{array}$ & & & & & 46 \\
\hline $\begin{array}{l}\text { Testosterone } \\
(8-29 \mathrm{nmol} / \mathrm{L})\end{array}$ & & & & $\begin{array}{l}6.4(\text { Oct } \\
2012)\end{array}$ & 10.3 \\
\hline $\begin{array}{l}\text { FSH (1-12 IU/L) } \\
\text { LH (0.6-12 IU/L) }\end{array}$ & & & $\begin{array}{l}\text { LH } 3 \text { FSH } \\
5\end{array}$ & & \\
\hline Comments & $\begin{array}{l}\text { Patient } \\
\text { taking } \\
\text { calcitriol, } \\
\text { phosphate } \\
\text { binders }\end{array}$ & $\begin{array}{l}\text { Patient } \\
\text { taking } \\
\text { calcitriol, } \\
\text { phosphate } \\
\text { binders }\end{array}$ & & L1\# & Bone biopsy \\
\hline
\end{tabular}


Table 3: Updated recommendations from the 2017 KDIGO guidelines on the diagnosis and treatment of CKD-MBD*(3)

\begin{tabular}{|c|c|c|c|c|}
\hline & 2009 KDIGO guidelines & 2017 KDIGO guidelines & Rationale & $\begin{array}{l}\text { Evidence } \\
\text { grade }{ }^{(81)}\end{array}$ \\
\hline \multicolumn{5}{|l|}{ Diagnosis } \\
\hline BMD by DXA & $\begin{array}{l}\text { In patients with CKD G3a-G5D } \\
\text { with evidence } \\
\text { of CKD-MBD, we suggest that } \\
\text { BMD testing not be } \\
\text { performed routinely, because } \\
\text { BMD does not } \\
\text { predict fracture risk as it does } \\
\text { in the general } \\
\text { population, and BMD does not } \\
\text { predict the type of } \\
\text { renal osteodystrophy }\end{array}$ & $\begin{array}{l}\text { In patients with CKD Stages 3a- } \\
5 \mathrm{D} \text { with evidence of CKD-MBD } \\
\text { and/or risk factors for } \\
\text { osteoporosis, BMD testing is } \\
\text { suggested to assess fracture } \\
\text { risk if results will impact } \\
\text { treatment decisions }\end{array}$ & $\begin{array}{c}\text { Four prospective cohort } \\
\text { studies of DXA BMD and } \\
\text { incident fractures in adults } \\
\text { with CKD stages } 3 a-5 D \\
\text { DXA BMD predicted fractures } \\
\text { across the spectrum from CKD } \\
\text { stages 3a to } 5 D\end{array}$ & $2 B$ \\
\hline Bone Biopsy & $\begin{array}{l}\text { In patients with CKD G3a-G5D, } \\
\text { it is } \\
\text { reasonable to perform a bone } \\
\text { biopsy in various } \\
\text { settings including, but not } \\
\text { limited to: unexplained }\end{array}$ & $\begin{array}{l}\text { In patients with CKD G3a-G5D, } \\
\text { it is } \\
\text { reasonable to perform a bone } \\
\text { biopsy if } \\
\text { knowledge of the type of renal } \\
\text { osteodystrophy }\end{array}$ & $\begin{array}{l}\text { The primary motivation for } \\
\text { this revision was } \\
\text { the growing experience with } \\
\text { osteoporosis } \\
\text { medications in patients with } \\
\text { CKD, low BMD, }\end{array}$ & Not graded \\
\hline
\end{tabular}

This article is protected by copyright. All rights reserved. 


\begin{tabular}{|c|c|c|}
\hline $\begin{array}{l}\text { fractures, persistent bone pain, } \\
\text { unexplained } \\
\text { hypercalcemia, unexplained } \\
\text { hypophosphatemia, } \\
\text { possible aluminum toxicity, } \\
\text { and prior to therapy } \\
\text { with bisphosphonates in } \\
\text { patients with CKD-MBD }\end{array}$ & $\begin{array}{c}\text { will impact treatment } \\
\text { decisions }\end{array}$ & $\begin{array}{l}\text { and a high risk of fracture. The } \\
\text { inability to } \\
\text { perform a bone biopsy may } \\
\text { not justify } \\
\text { withholding antiresorptive } \\
\text { therapy from } \\
\text { patients at high risk of } \\
\text { fracture. }\end{array}$ \\
\hline
\end{tabular}

\section{Treatment}

Bisphosphonates

(and other

osteoporosis

medications)
In patients with CKD G4-G5D having

biochemical abnormalities of CKD-MBD, and low

$B M D$ and/or fragility fractures, we suggest

additional investigation with bone biopsy prior to

therapy with antiresorptive agents
In patients with CKD G3a-G5D with biochemical

abnormalities of CKD-MBD and low BMD and/or fragility

fractures, we suggest treatment choices take into account the magnitude and reversibility of the biochemical abnormalities and the progression of CKD, with consideration of a bone biopsy
The primary motivation for this revision was

the growing experience with osteoporosis

medications in patients with CKD, low BMD,

and a high risk of fracture. The inability to

perform a bone biopsy may not justify

withholding antiresorptive therapy from

patients at high risk of fracture. 
*These represent a select number of clinical updates from the 2017 KDIGO guidelines and are not a complete summary. 
Figure 1: DXA scan results
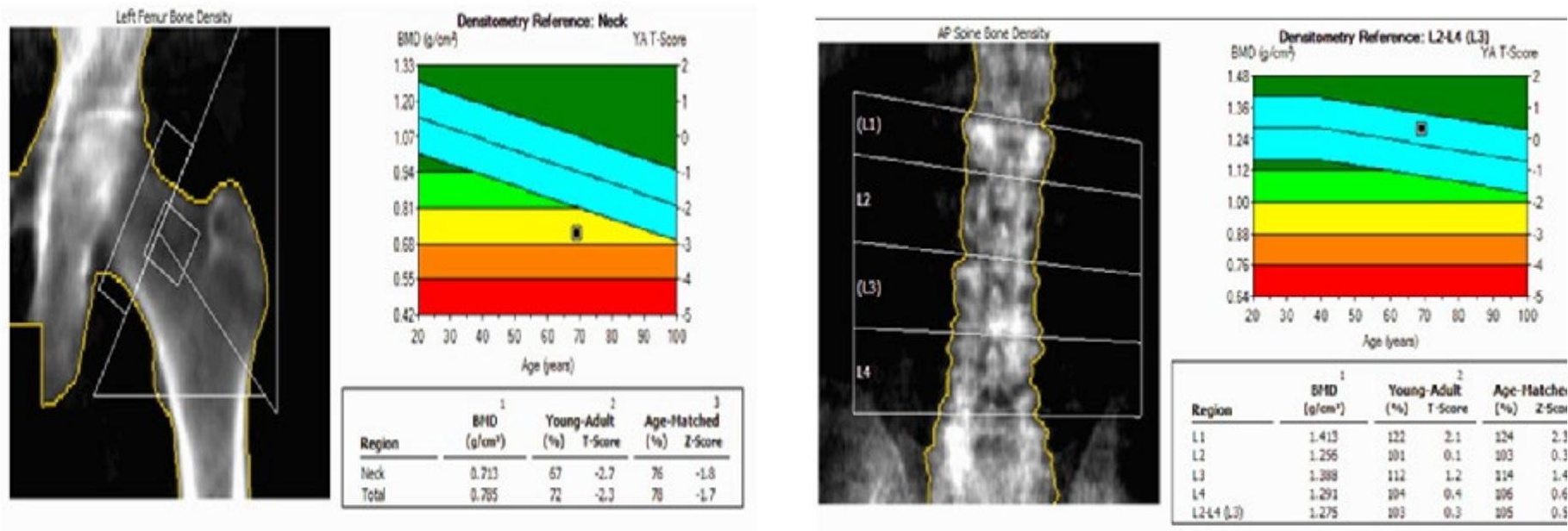

This article is protected by copyright. All rights reserved. 
Figure 2: Bone biopsy histology

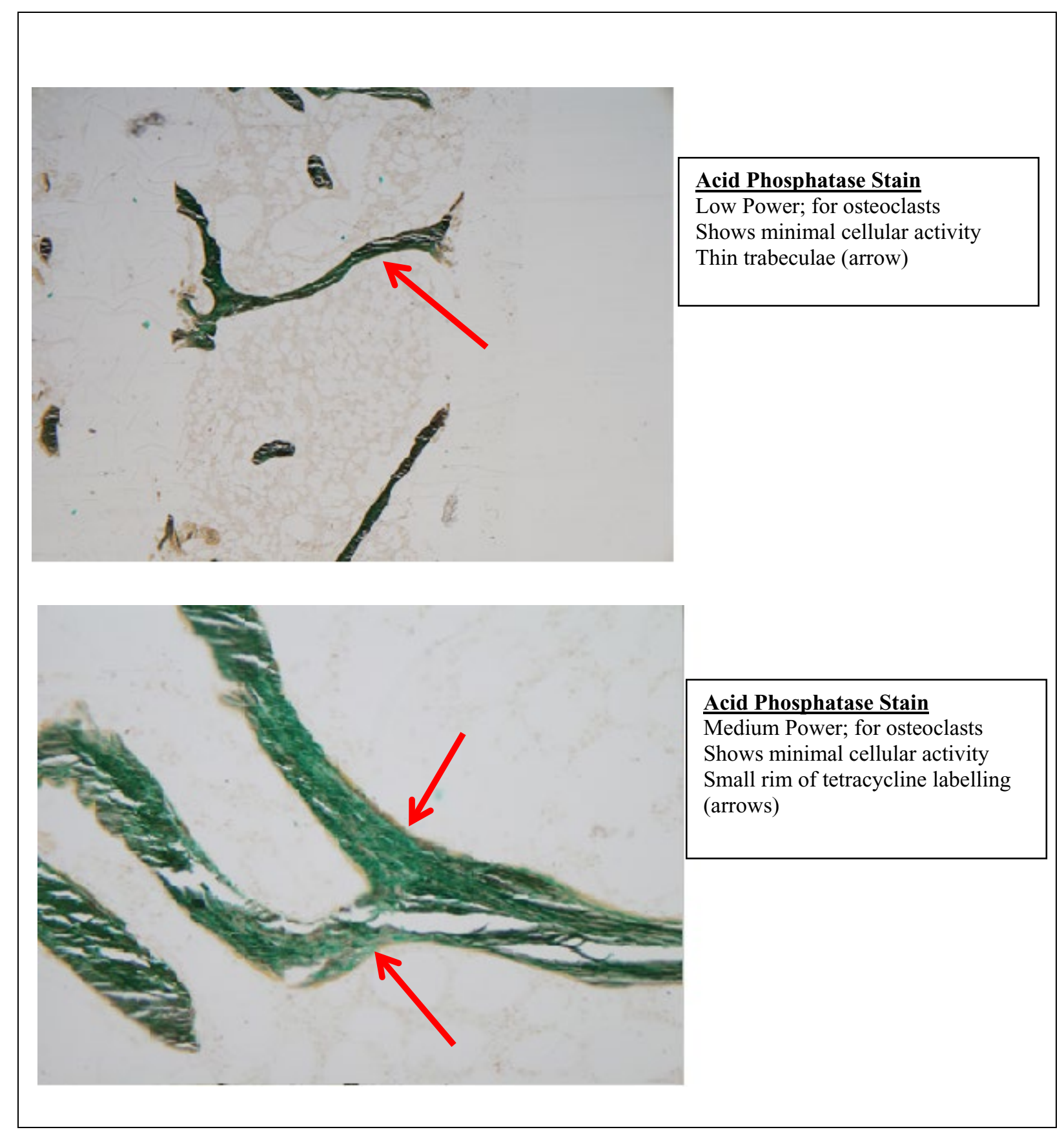

This article is protected by copyright. All rights reserved. 


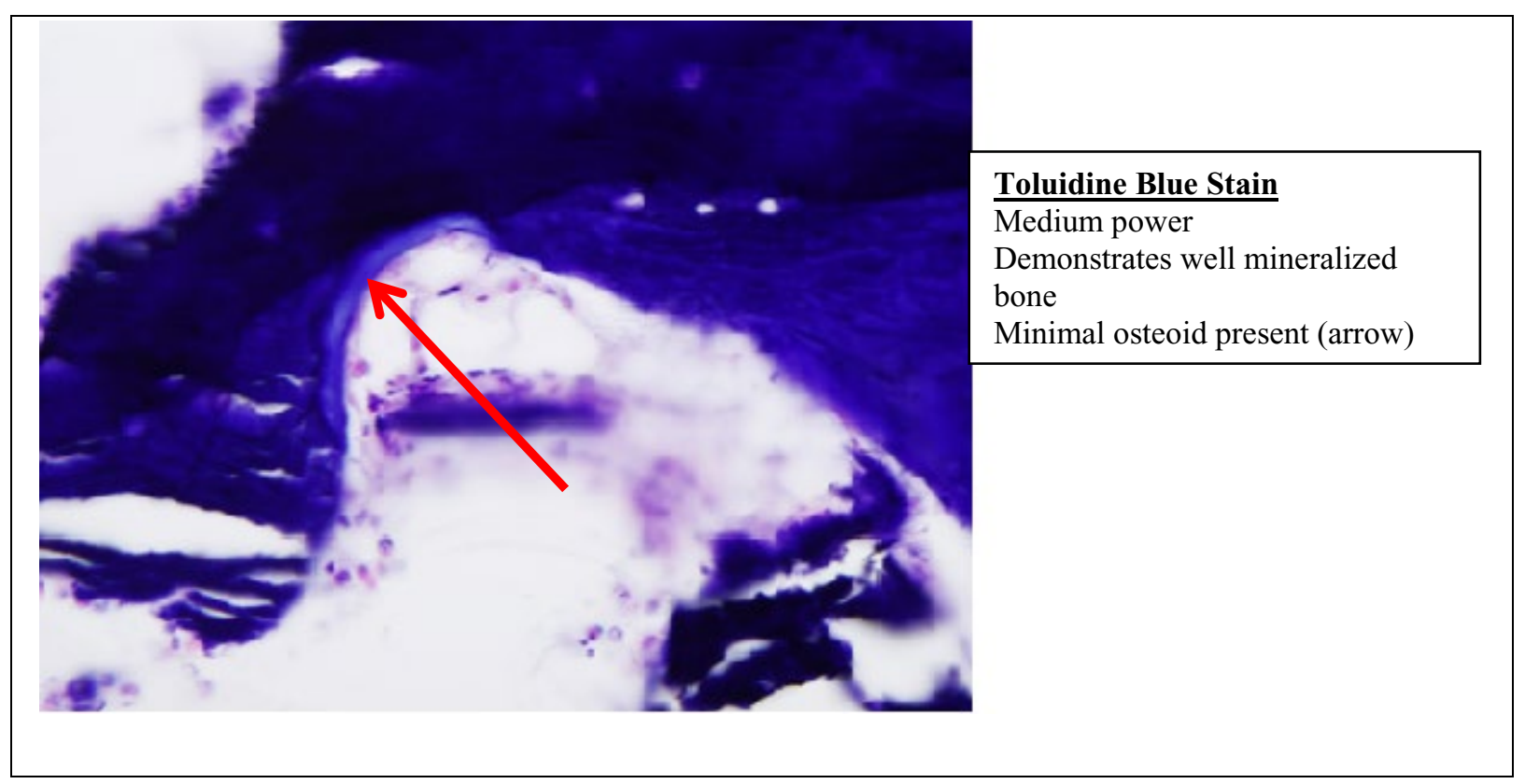

This article is protected by copyright. All rights reserved. 


\begin{abstract}
The metabolic abnormalities affecting bone in the setting of chronic kidney disease (CKD) are complex with over-lapping and inter-acting aetiologies and have challenging diagnostic and management strategies. Disturbances in calcium, phosphate, fibroblast growth factor 23, parathyroid hormone $(\mathrm{PTH})$ concentrations and vitamin D deficiency are commonly encountered and contribute to the clinical syndromes of bone disorders in CKD including hyperparathyroidism, osteomalacia, osteoporosis and adynamic bone disease. Mineral and bone abnormalities may also persist or arise de novo post-renal transplantation. The Kidney Disease Improving Global Outcomes (KDIGO) organisation describes these mineral metabolism derangements and skeletal abnormalities as 'CKD Mineral and Bone Disorder' (CKD-MBD). Patients with this disorder have an increased risk of fracture, cardiovascular events and overall increased mortality. In light of the recently updated 2017 guidelines from the KDIGO, we present a clinical case-based discussion to highlight the complexities of investigating and managing the bone health of patients with CKD with a focus on these updates.
\end{abstract}

Key words: Chronic Kidney Disease, Metabolic bone disease, Fractures

This article is protected by copyright. All rights reserved. 


\section{Bone Health in Chronic Kidney Disease-Mineral and Bone Disorder}

\section{A Clinical Case Seminar and Update}

Aleksova $\mathrm{J}^{1,2,3.4}, \mathrm{Ng} \mathrm{KW}^{4}$, Jung $\mathrm{C}^{4}$, Zeimer $\mathrm{H}^{4}$, Dwyer $\mathrm{KM}^{5}$, Milat $\mathrm{F}^{1,2,3}$ \& MacIsaac $\mathrm{RJ}^{4,6}$

1. Hudson Institute for Medical Research, Clayton 3168, Australia

2. Department of Medicine, Monash University, Clayton 3168, Australia

3. Department of Endocrinology, Monash Health, Clayton 3168, Australia

4. Department of Endocrinology \& Diabetes, St Vincent's Hospital Melbourne

5. School of Medicine, Faculty of Health, Deakin University, Burwood, Victoria, Australia

6. Department of Medicine, University of Melbourne

Correspondence: Dr Jasna Aleksova MBBS (HONS), FRACP

Endocrinology Department, Monash Health, 246 Clayton Rd, Clayton, VIC 3168,

AUSTRALIA. Email: Jasnaaleksova@hudson.org.au

\section{Pages: 29}

Review word count: 3464

\section{Abstract word count: 155}

Tables: 3

Figures: 2 


\section{University Library}

\section{- M M N E R VA A gateway to Melbourne's research publications}

Minerva Access is the Institutional Repository of The University of Melbourne

\section{Author/s:}

Aleksova, J;Ng, KW;Jung, C;Zeimer, H;Dwyer, KM;Milat, F;Maclsaac, RJ

Title:

Bone health in chronic kidney disease-mineral and bone disorder: a clinical case seminar and update

Date:

2018-12-01

\section{Citation:}

Aleksova, J., Ng, K. W., Jung, C., Zeimer, H., Dwyer, K. M., Milat, F. \& Maclsaac, R. J. (2018). Bone health in chronic kidney disease-mineral and bone disorder: a clinical case seminar and update. INTERNAL MEDICINE JOURNAL, 48 (12), pp.1435-1446. https:// doi.org/10.1111/imj. 14129.

Persistent Link:

http://hdl.handle.net/11343/284583 